Viso - Cadernos de estética aplicada Revista eletrônica de estética

ISSN 1981-4062

No 24, jan-jun/2019

http://www.revistaviso.com.br/
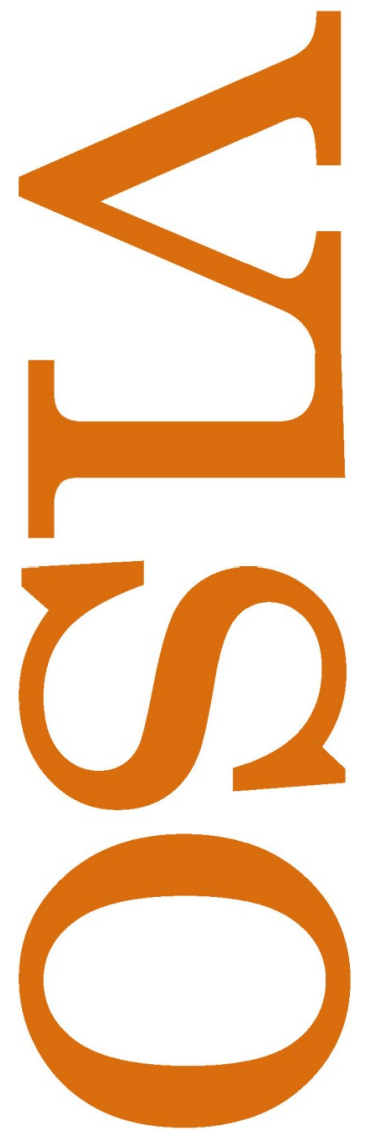

\title{
Entre o gesto do colecionador e a arte da miniatura Francisco Camêlo
}

Pontifícia Universidade Católica do Rio de Janeiro (PUC-RIO)

Rio de Janeiro, Brasil 


\section{RESUMO}

\section{Entre o gesto do colecionador e a arte da miniatura}

Propõe-se uma articulação entre os gestos de colecionar e miniaturizar, em conexão com o imaginário da infância, a partir do pensamento de Walter Benjamin. Sabe-se que, além de ter escrito ensaios sobre a ação de colecionar e a figura do colecionador, Benjamin foi colecionador e tinha apreço pelo pequeno (miniaturas, brinquedos, selos, cartões postais, escrita). Seu método de trabalho enfatizava o pormenor, o detalhe, os aspectos aparentemente insignificantes de seus objetos de estudo, como a Paris de Baudelaire ou a dos surrealistas, esta última um "pequeno mundo". Esta metodologia, cuja atenção se volta para o minúsculo, está articulada tanto à apresentação da filosofia como uma mônada quanto a um sentimento infantil de Benjamin, como afirma Susan Sontag no ensaio "Sob o signo de Saturno" (1986). Com base nessa atração infantil pelo pequeno e na figura do colecionador, isto é, daquele que, qual uma criança, consegue olhar de forma diferente um objeto, esta comunicação perseguirá afinidades entre o imaginário da infância e as ações de colecionar e miniaturizar, em reflexão cruzada tanto com artistas visuais que compõe séries com objetos em miniatura quanto com escritores colecionadores.

Palavras-chave: Medeia - Pasolini - Eurípides - tragédia - crítica da cultura

\section{ABSTRACT}

\section{Between the Gesture of Collector and the Art of Miniature}

It proposes a joint between the gesture of collecting and miniaturizing, connecting with the childhood's imaginary based on Walter Benjamin's thought. It is known that besides writing essays on the action of collecting and the figure of the collector, Benjamin was a collector himself and he has esteem for the small things (miniatures, toys, stamps, postal cards, handwritings). His method of work emphasizes the detail, the particular and the aspects apparently insignificants of his study objects as the Paris in Baudelaire's or the French surrealism. This methodology's attention is devoted to the tiny and it is articulated as well in the presentation of the philosophy as a monad as in childlike feelings, as said by Susan Sontag on the essay "Under the sign of Saturn" (1986). Based on this infantile attraction for the small and on the collector's figure, that is the one who, as a child, is allowed to look differently a object, this paper chases affinities between the childhood's imaginary, the action of collecting and of miniaturizing in a crossed reflexion with visual artists that compose series with small objects and with collector writers.

Keywords: Walter Benjamin - collection - miniature - childhood 
CAMÊLO, F. "Entre o gesto do colecionador e a arte da miniatura". In: Viso: Cadernos de estética aplicada, v. XII, n. 24 (jan-jun/2019), pp. 148-167.

DOI: 10.22409/1981-4062/v24i/315

Aprovado: 19.01.2019. Publicado: 30.06.2019.

(c) 2019 Francisco Camêlo. Esse documento é distribuído nos termos da licença Creative Commons Atribuição-NãoComercial 4.0 Internacional (CC-BY-NC), que permite, exceto para fins comerciais, copiar e redistribuir o material em qualquer formato ou meio, bem como remixá-lo, transformá-lo ou criar a partir dele, desde que seja dado o devido crédito e indicada a licença sob a qual ele foi originalmente publicado.

Licença: http://creativecommons.org/licenses/by-nc/4.0/deed.pt_BR

Accepted: 19.01.2019. Published: 30.06.2019.

(C) 2019 Francisco Camêlo. This document is distributed under the terms of a Creative Commons Attribution-NonCommercial 4.0 International license (CC-BY-NC) which allows, except for commercial purposes, to copy and redistribute the material in any medium or format and to remix, transform, and build upon the material, provided the original work is properly cited and states its license.

License: http://creativecommons.org/licenses/by-nc/4.0/ 
Quem, um dia, começou a abrir o leque da lembrança, sempre encontra novos segmentos, novos bastõezinhos, nenhuma imagem lhe basta, pois reconheceu o seguinte: ela se deixaria desdobrar, somente nas dobras está o verdadeiro: esta imagem, este gosto, este toque em vista do qual abrimos, desdobramos tudo isso; e agora a lembrança vai do pequeno ao menor, dos menores ao mais minúsculo e aquilo que vem ao seu encontro nestes microcosmos adquire uma violência cada vez maior. ${ }^{1}$ Walter Benjamin, Crônica berlinense

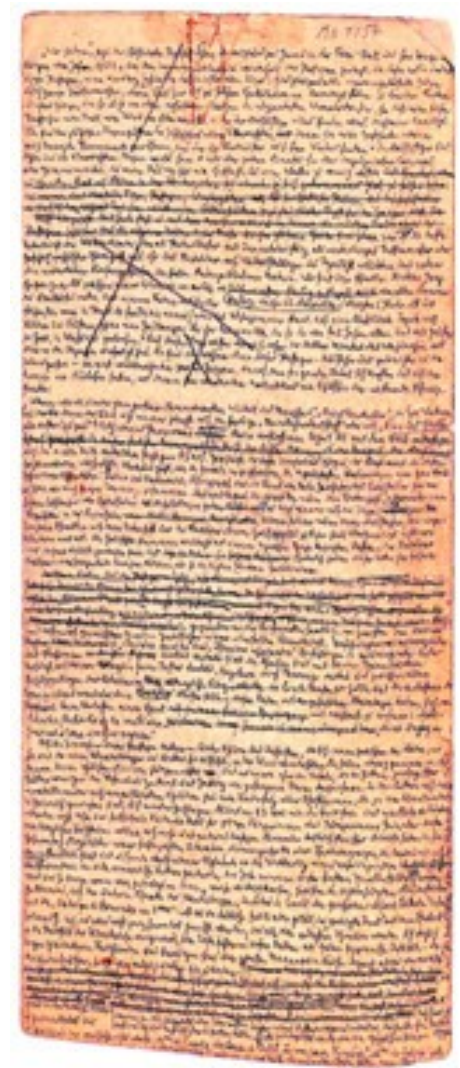

Figura 1: Caligrafia de Walter Benjamin no manuscrito de Passagens

Colecionador de brinquedos e livros infantis, filósofo da "história constelar" atraído por objetos kitsch e insignificantes, escritor melancólico de caligrafia microscópica, Walter Benjamin construiu sua obra com a "miniatura dos Denkbilder" ${ }^{2}$ (imagens de pensamento). Usou sua coleção de citações recolhidas de livros da Bibliothèque Nationale e seus passeios pelas passagens parisienses para montar sua história do século XIX e das primeiras décadas do XX; reconheceu no mundo da infância uma temporalidade intermitente feita com gestos mágicos, plásticos e violentos. Veja-se o efeito de uma das peças [Stück $]^{3}$ que compõem sua singular narrativa autobiográfica, Infância berlinense: 1900, onde reencena uma "Manhã de inverno". A imagem daquele dia frio, que conectava o menino judeu aos objetos de seu quarto burguês, serviu-lhe para ler o que não estava escrito: no desejo infantil de dormir à vontade decifrou a própria inaptidão de conseguir uma situação financeira estável. O desdobrar da imagem 
do passado no agora da escrita abre uma dinâmica entretempos que origina a compreensão do presente a partir dos restos da memória infantil.

Quando fez a "Caracterização de Walter Benjamin", Theodor Adorno sublinhou o protagonismo que a infância tem no conceito de linguagem e na teoria da história de Benjamin de tal modo que o que ele "dizia e escrevia soava como se o seu pensamento assumisse as promessas dos contos de fadas e dos livros infantis [...] e isso de um modo tão radical e literal que torna perceptível até mesmo a real efetivação do conhecimento". ${ }^{4}$ Alguns poucos exemplos já evidenciam o destaque, nos escritos benjaminianos, da figura alegórica da criança, capaz não só de "fazer história dos detritos da História", mas de acessar o "arquivo de semelhanças não sensíveis" da linguagem, já que para as crianças "as palavras ainda são como cavernas entre as quais conhecem os mais estranhos caminhos de ligação". ${ }^{5}$ Se essa exploração da linguagem dá notícias da antiga faculdade de ler semelhanças, outrora tão decisiva para os povos arcaicos, que liam o destino dos homens a partir da posição das estrelas, os jogos infantis evidenciam comportamentos miméticos, que muitas vezes brincam arriscadamente com a morte. Leiam-se as emblemáticas peças "Esconderijos" e "Caça às borboletas". De um lado, a criança abandona temporariamente sua condição humana para se camuflar no esconderijo; de outro lado, ela aproxima-se perigosamente da essência do inseto para capturá-lo; em ambas, o assujeitamento imposto pela ação de brincar e de caçar ocasiona uma experiência de quase morte.

Esse aspecto violento dos jogos infantis também caracteriza o gesto do colecionador. Por definição, toda coleção é lacunar e incompleta, o que justifica o impulso anarquista e destrutivo do colecionador, que arranca o objeto de seu contexto original para acrescentá-lo a um conjunto de peças, modificando seu valor. Opondo-se ao alegorista, que desistiu de reunir as coisas e para quem estas representam "verbetes de um dicionário secreto", o colecionador encerra cada coisa em uma enciclopédia ou em um círculo mágico onde ela, a coisa, se imobiliza, enquanto a percorre o estremecimento de ser adquirida. ${ }^{6} \mathrm{O}$ método violento do colecionador para possuir as coisas evoca "O caráter destrutivo". Neste pequeno ensaio escrito em 1931, o gesto de destruir é qualificado como ativo, jovem e alegre; a imagem do destruidor é descrita como a daquele que simplifica o mundo à medida que vai abrindo espaço, já que não vê nada de duradouro, e sim caminhos por toda parte. Às vezes o faz com força bruta, outras com requinte, mas sempre convertendo em ruínas tudo o que existe, menos pelas ruínas e mais pelas passagens que as atravessam. Com gestos destrutivos, a criança também não conhece nada de permanente; ela destroça seus brinquedos para ver do que são feitos e arranca as coisas de seus contextos, desenfeitiçando seus sentidos originais e as encerrando num mundo de sonho.

No ensaio "A paixão do colecionar", a filósofa Maria Filomena Molder ${ }^{7}$ chama atenção para a "energia semântica" de três palavras alemãs "sammeln" (reunir), "sich sammeln" (recolher) e "Sammlung" (colecionar) que certamente impressionaram Walter Benjamin, 
aumentando sua atração por tudo que era pequeno, como miniaturas, brinquedos, selos, cartões postais ou ainda dois grãos de trigo onde estava escrito todo o Schema Israel. É Hannah Arendt ${ }^{8}$ quem conta esse episódio ocorrido no Museu de Cluny, em Paris, para afirmar, em seguida, que o interesse de Benjamin pelo minúsculo provém da convicção de que quanto menor fosse o objeto, mais provável pareceria poder conter tudo sob a mais concentrada forma. Para Susan Sontag ${ }^{9}$, o olhar curioso de Benjamin para o pequeno e o insignificante resulta de sua preferência por formas narrativas breves e da percepção de que as coisas em vias de desaparecimento possuem uma energia revolucionária, a exemplo dos brinquedos russos manufaturados comprados por ele quando fora à Rússia visitar a diretora de teatro infantil Asja Lacis, como se lê no Diário de Moscou.
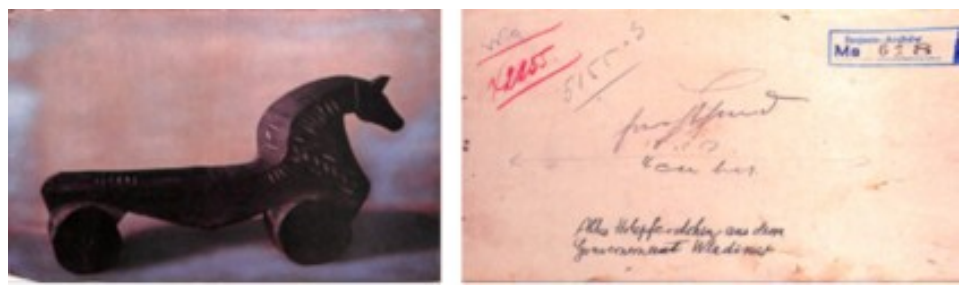

Figura 2: Fotografia de brinquedos russos com anotações de Walter Benjamin
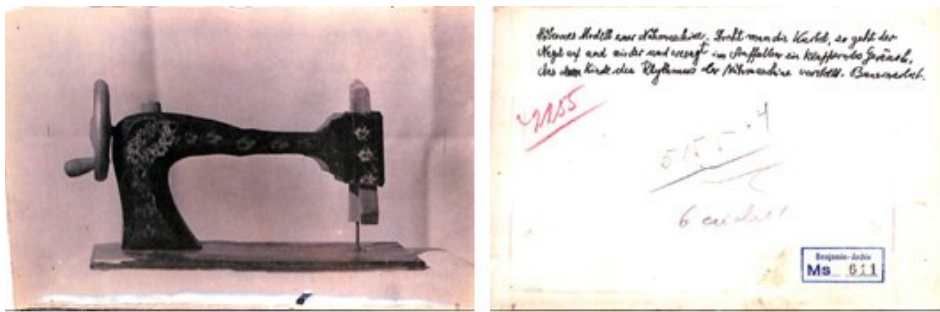

Figura 3: Fotografia de brinquedos russos com anotações de Walter Benjamin

Como apontou recentemente Gerhard Richter, a procura atenta e meticulosa de Benjamin pelo não monumental é um gesto eminentemente político, que recusa a condição de insignificância dos objetos culturais como algo natural. Tal atitude é a semente de uma historiografia radicalmente inovadora construída não da cultura oficial, mas dos detritos e daquilo que foi marginalizado. Nesse sentido, o fragmento "Canteiro de obra", de Rua de mão única, é emblemático não só porque descreve a capacidade das crianças de construir novas formas com materiais negligenciados, mas também porque apresenta Benjamin como o colecionador e o trapeiro do lixo da história. ${ }^{10}$

Assim como Benjamin, também os artistas visuais Willard Wigan e Márcia X sentem-se atraídos por brinquedos e objetos minúsculos. Com gestos lúdicos e violentos, manipulam seus materiais de trabalho, fazem pequenas intervenções em brinquedos, constroem com coisas diminutas uma coleção de imagens - às vezes oníricas, outras vezes eróticas - explorando a energia e a plasticidade da infância. Assim, ampliam as possibilidades do jogo infantil, tornando expansivo o campo da criação e escrevendo uma outra história da infância, menos autorreferente e mais informe. 
Quando viu o pequeno Willard Wigan construindo casas para formigas e outros insetos, sua mãe teria dito: "Você se tornará grande fazendo coisas pequenas". Desde então, o menino empenhou-se na brincadeira de mostrar que as coisas pequenas podem ser maiores. Com paciência e disciplina física, passou a esculpir miniaturas em grãos de areia e fibras de pó ao ouro, posicionando-as no buraco de uma agulha ou na cabeça de um alfinete. Esses pequenos mundos, onde figuras dos contos de fadas são redesenhadas em dimensões liliputianas, variam de tamanho (de 0,0002 a 0,005 mm) e são construídos através de um método meditativo que retarda a frequência cardíaca do artista.

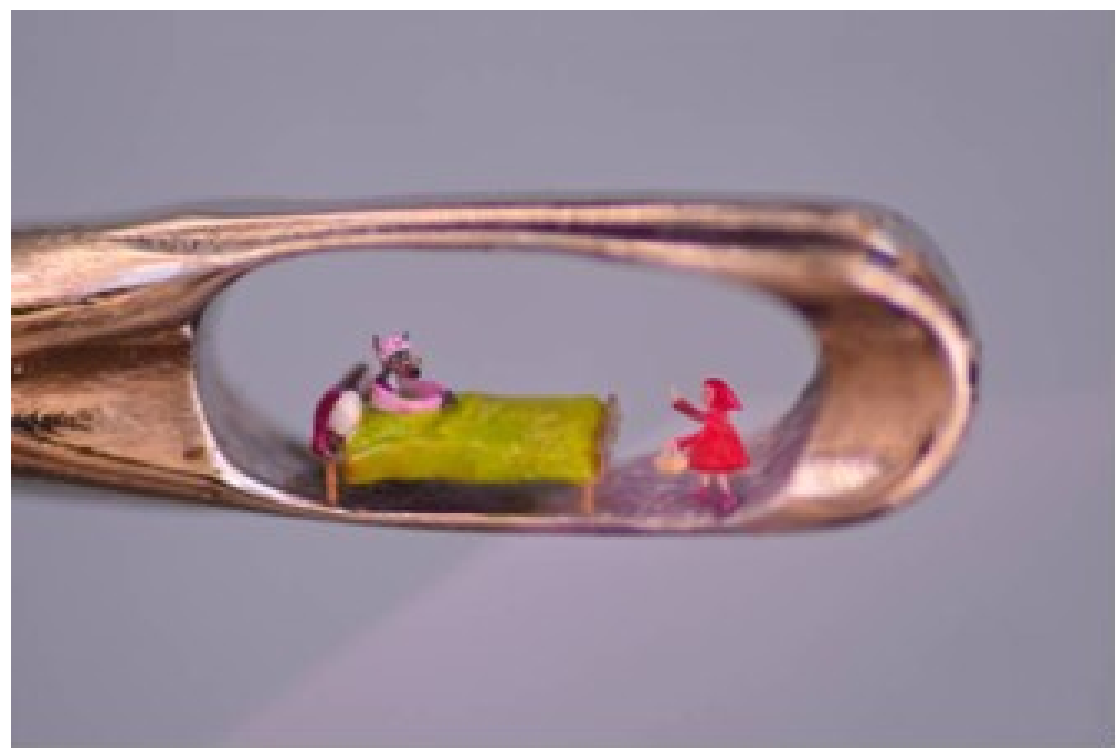

Figura 4: Miniatura de Willard Wigan 


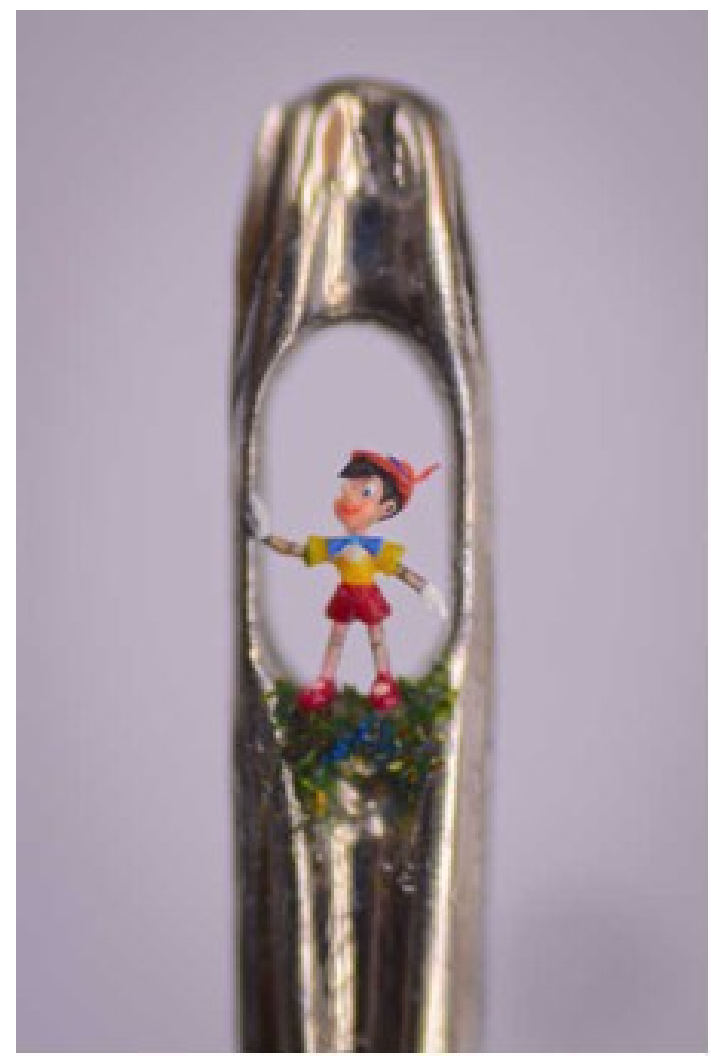

Figura 5: Miniatura de Willard Wigan

A temporalidade desacelerada no ato da criação guarda semelhança com a leitura que Susan Sontag fez da vida e da obra de Benjamin, a partir da astrologia. Para a ensaísta, o signo de Saturno, planeta das revoluções mais lentas sob o qual o pensador alemão nasceu, regeu seu temperamento melancólico e influenciou seus principais temas de reflexão. A energia saturnina constela em torno de cada escrito de Benjamin, impeliandoo tanto a um "recuo à interiorização" 11 quanto à "valorização da exterioridade, que se faz num movimento de evasão, de entrega total às minúcias da realidade concreta, onde a intenção subjetiva se apaga no objeto e o pensamento, agarrado à coisa, transforma-se num tatear, em um cheirar e em um saborear", segundo a caracterização de Adorno. A entrega total à exterioridade das coisas diz da imersão de Benjamin nos espaços urbano e textual e de sua atenção minuciosa ao pormenor, ao detalhe, aos aspectos aparentemente insignificantes dos seus objetos de estudo. Ambas as experiências estão inscritas em uma outra temporalidade, certamente não a do progresso, que empurra o Angelus Novus, de Paul Klee (também ele um colecionador) para o futuro, mas a que conecta esse anjo de feição e traço infantis com o amontoado de ruínas do passado. 


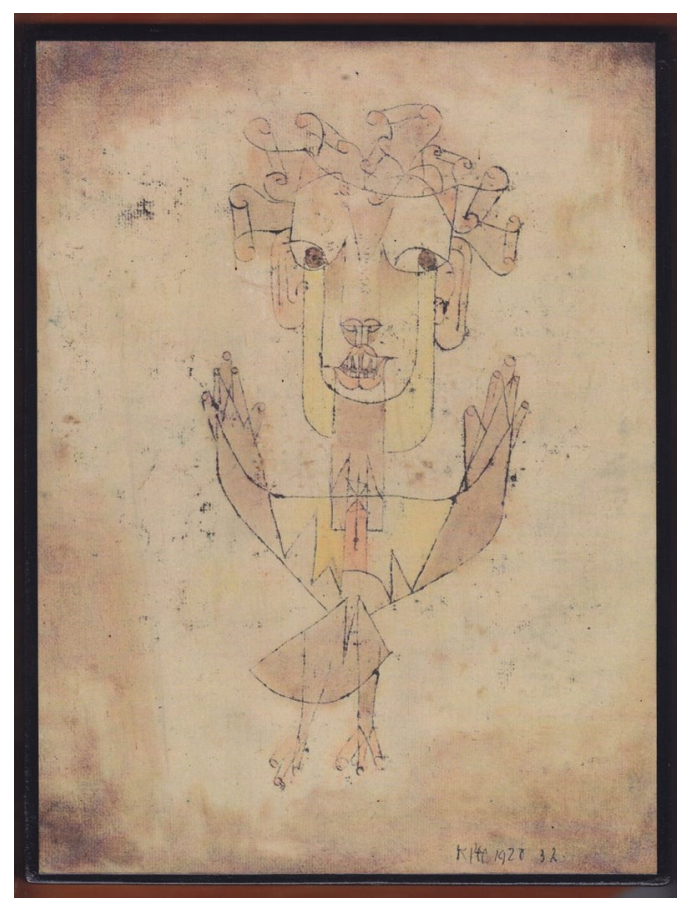

Figura 6: Angelus Novus, Paul Klee, 1920

Essa temporalidade vagarosa conduz o movimento desacelerado de Willard Wigan, que, entre um batimento e outro e com precisão técnica extenuante, refigura personagens de histórias infantis em pequeníssimos mundos onde "o acesso final à sua interioridade e aos segredos que podem conter nos é negado para sempre". ${ }^{12} \mathrm{O}$ retardamento do ritmo cardíaco e a dimensão de cifra das miniaturas de Wigan lembram não só o método lento e desviante de Benjamin, mas também o efeito de retard (atraso) produzido pela anti-arte de Marcel Duchamp, cujas obras substituem "o olhar (regard) pelo atraso (retard)", mostrando que "o invisível não é da ordem do obscuro", mas de "uma transparência turva que força o espectador a pensar," como observa Raúl Antelo no livro Maria com Marcel. ${ }^{13}$ Recorde-se, por exemplo, a última criação duchampiana, Étant Donnés (19461966), em que o observador precisa olhar com atenção através de dois pequenos buracos feitos numa porta de madeira para ter acesso a uma espécie de segredo da obra, o nu feminino escondido num pequeno quarto. 


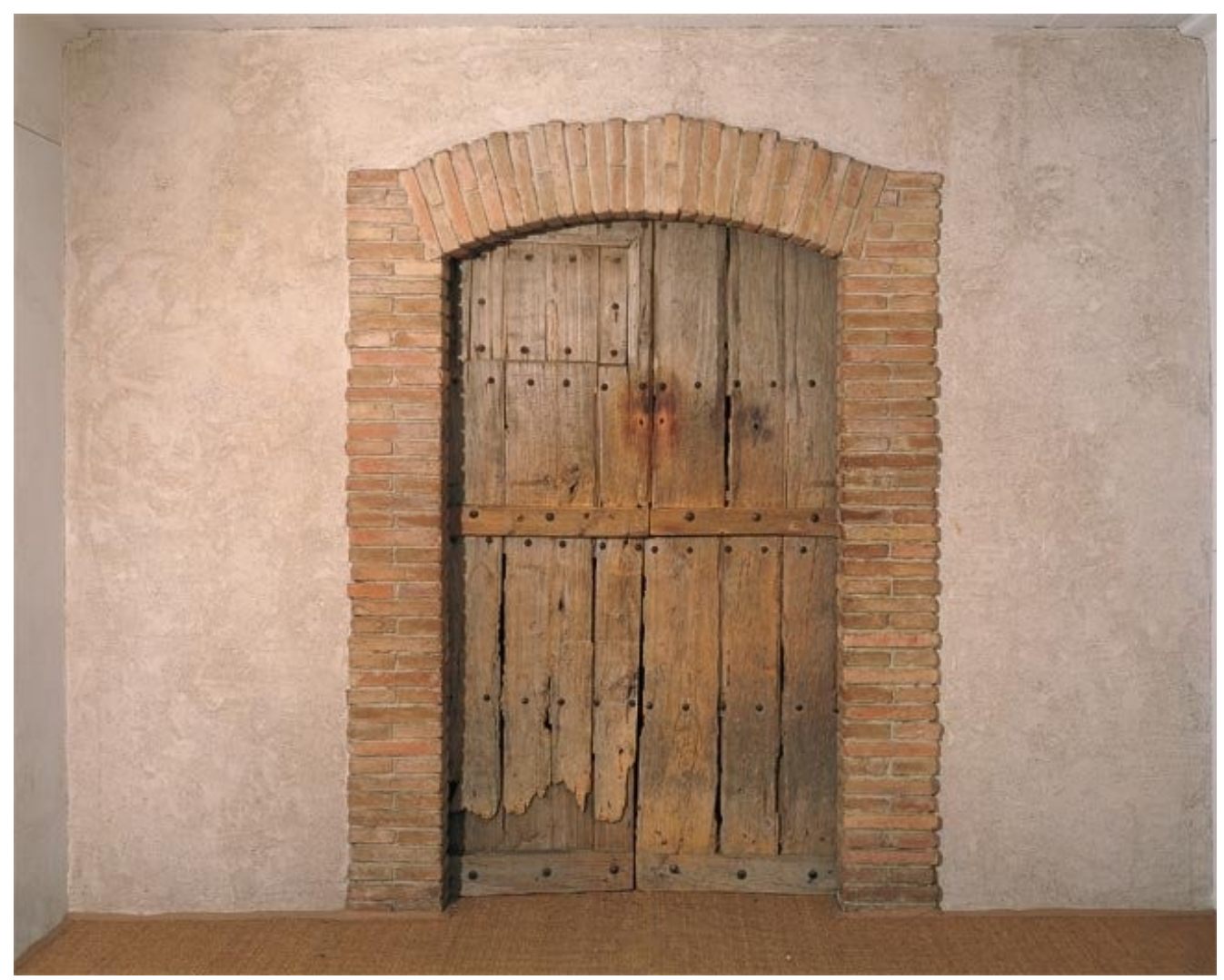

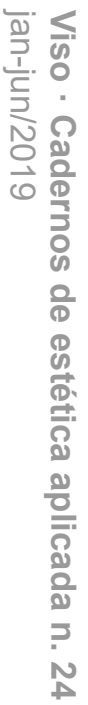

Figura 7: Étant donnés, Duchamp, 1946-1966

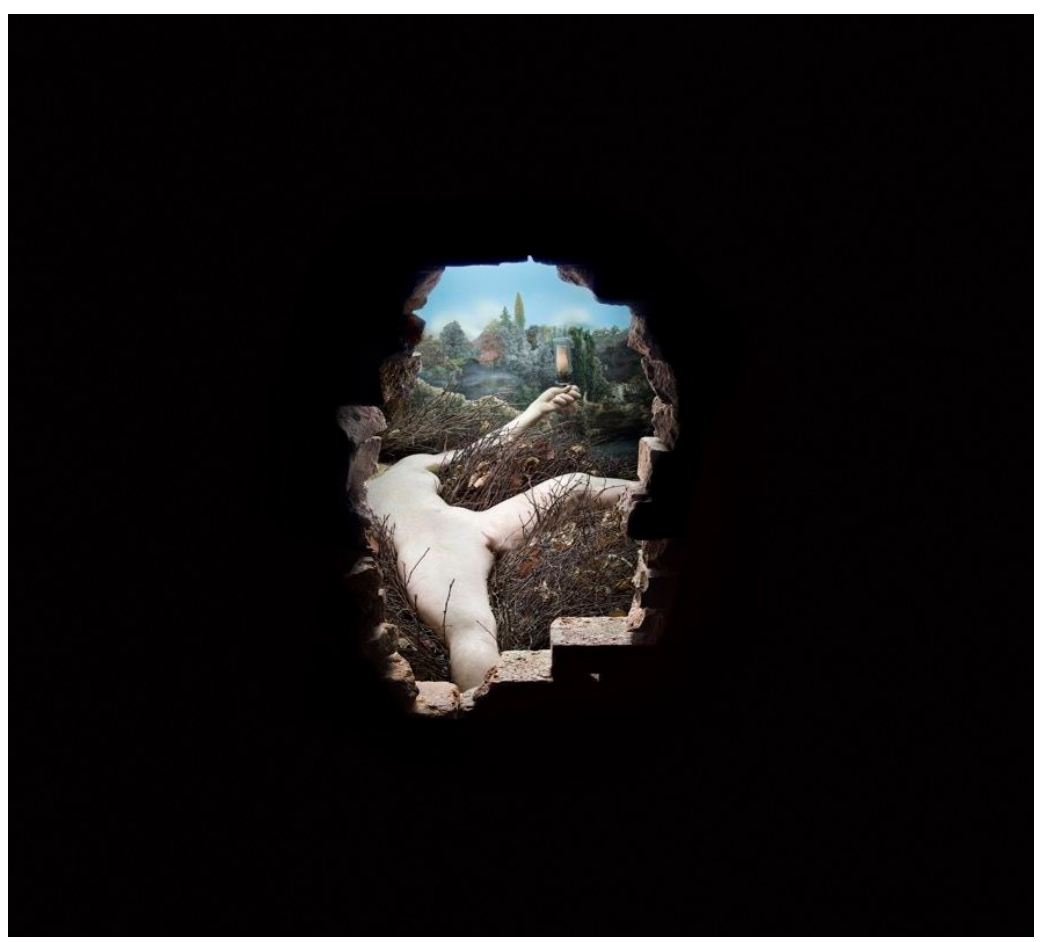

Figura 8: Étant donnés, Duchamp, 1946-1966 
Embora a dimensão de segredo não esteja presente nos trabalhos de Márcia X, sua obra "desabrida" possui uma semelhança sugestiva com o Étant donnés, no que diz respeito ao tratamento erótico dado pela artista às coisas kitsch, aos pênis de plástico e aos brinquedos do universo feminino (bonecas, espelhos, caixas de música, bijuterias), que comprava em lojas do comércio popular e em sex shops. Fábrica Fallus (1993-2005) é o título de uma série em que pênis de plásticos são transformados em bonecos, ora vestidos com pompons e rendas, ora cheios de medalhinhas, ou inseridos em redomas, como se fossem peças sacras. Os objetos retirados das prateleiras das lojas pela colecionadora ganham uma dupla feição: fálica e feminina, pornográfica e infantil, sagrada e profana. ${ }^{14}$ Assim, não só "o teológico penetra no reino do kitsch" ${ }^{15}$, mas também o infantil e o erótico.

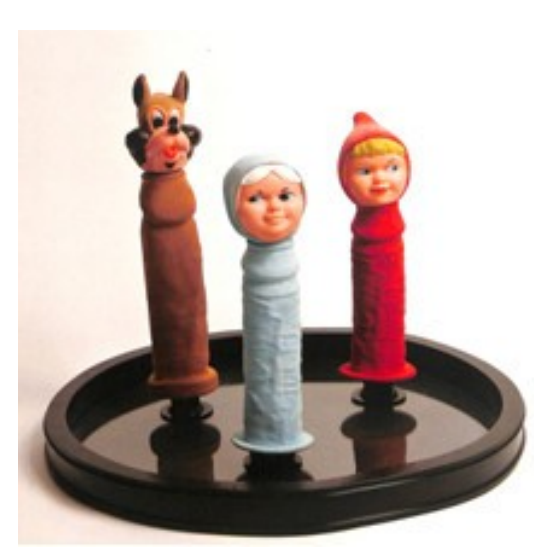

Figura 9: Sem título, Fábrica Fallus, s/d

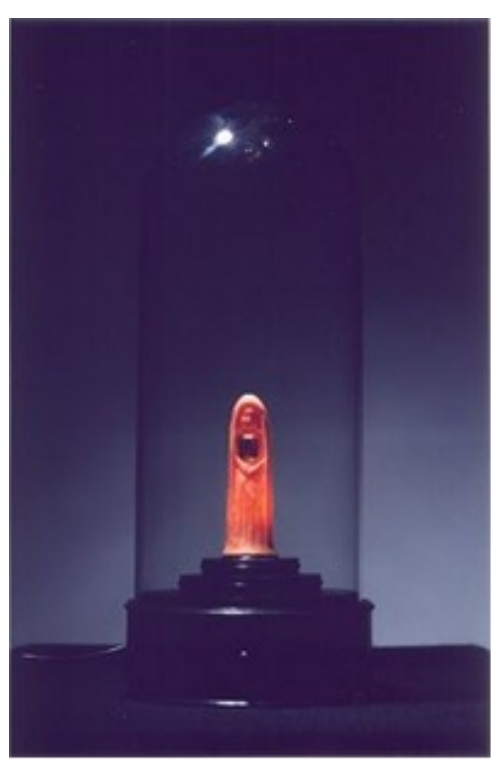

Figura 10: En nombre del Padre, Fábrica Fallus, 1994

Se Fábrica Fallus mostra a apropriação lúdica e profana de objetos, na instalação Os Kaminhas Sutras (1995) o que está em jogo é a transformação perversa de brinquedos em personagens de uma cena erótica. Duplas e trios de bonecos em posição sexual estão dispostos em pequenas camas coloridas, com lençóis e travesseiros feitos de tecidos infantis. Todos os bonecos estão despidos e não possuem cabeça, o que thes garante o anonimato e a indistinção de gênero masculino/feminino. Encaixados uns nos outros por finíssimos cabos de aço, movem braços e pernas quando se aciona um pedal, numa coreografia de movimentos sexuais ao som da música tema da Disneylândia "It's a small world". Ao contrário da lentidão que preside o trabalho de Wigan e do aspecto cifrado de suas miniaturas, a obra explícita de Márcia X situa-se em uma temporalidade mais frenética, que nos leva a afirmar que as miniaturas, por si sós, não significam isto ou aquilo. Sua inserção em dinâmicas criativas específicas pode alterar radicalmente os efeitos que elas produzem e aquilo que se pode dizer delas. 


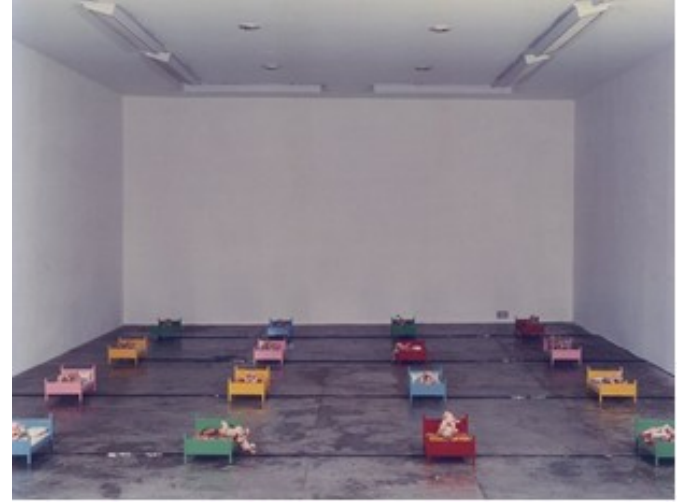

Figura 11: Os Kaminhas Sutras, 1995

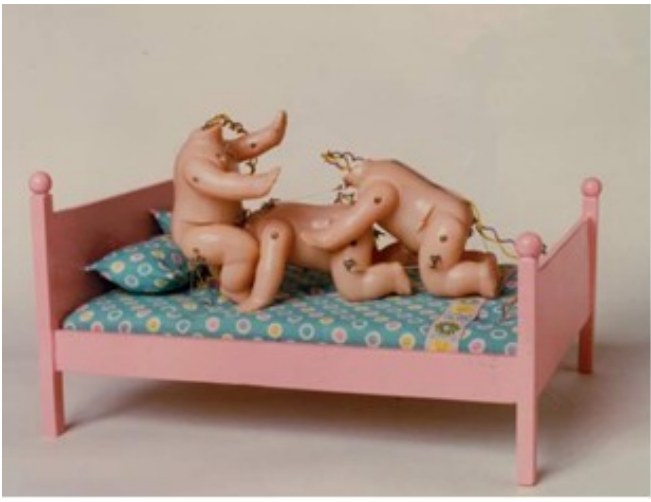

Figura 12: Os Kaminhas Sutras, 1995

Num texto sobre Os Kaminhas Sutras, Márcia X observa que "a cacofonia de sons intensifica a violência da movimentação mecânica contrastando com o visual adocicado" da instalação. Essa observação da artista poderia servir também de comentário à intervenção Tricyc(l)age - música para duas bicicletas e piano, realizada anos antes, em 1986, quando ela, pedalando um velocípede, invadiu um concerto em homenagem a John Cage, para perplexidade da plateia e do próprio compositor que, dizem, gostou da performance. $\mathrm{O}$ velocípede pertencia aos sobrinhos da artista e produzia um barulho, "um nhec nhec" que "ia ao encontro de uma sonoridade atonal, de uma melodia estranha". ${ }^{16} \mathrm{O}$ único registro daquela noite é uma fotografia em que Márcia $\mathrm{X}$ aparece pedalando o veículo infantil e segurando um cartaz onde se lê: "Ser serrote não é defeito, defeito é viver serrando".

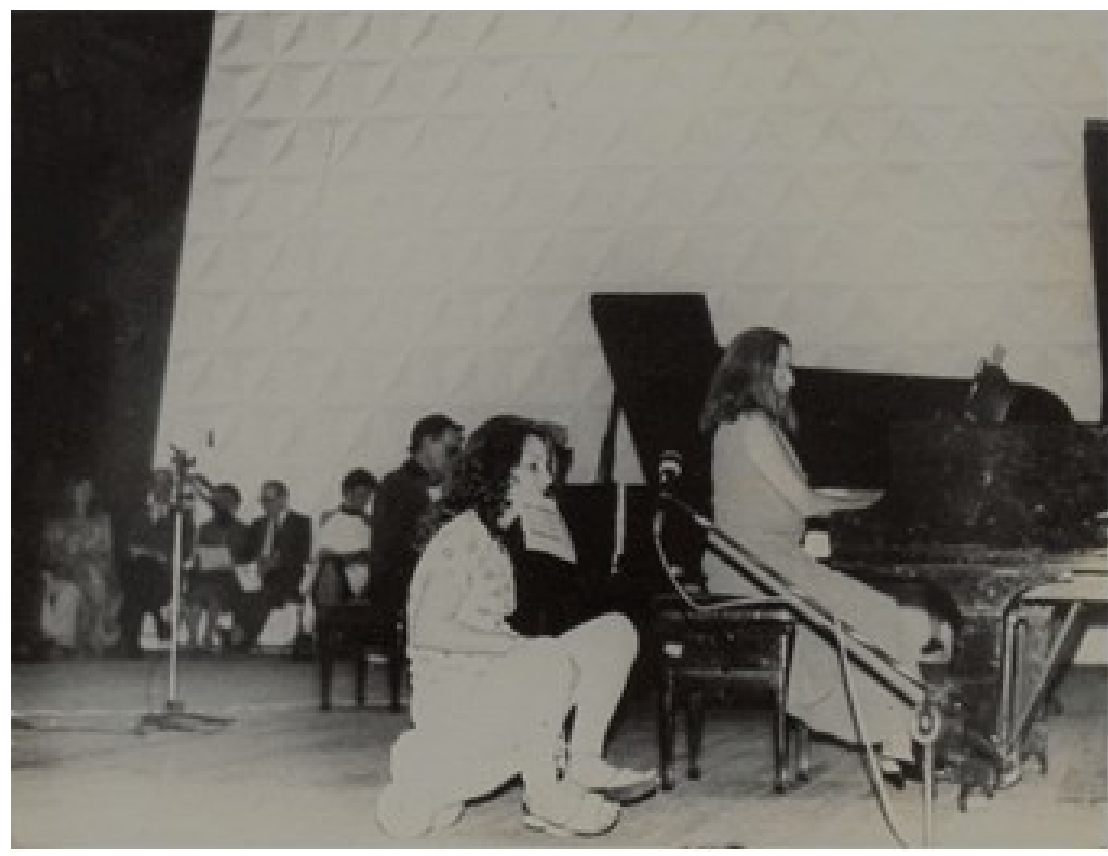

Figura 13: Fotografia de Marcia X na intervenção Tricyc(l)age, 1986 
A imagem de Márcia $X$ no minúsculo velocípede, pequena em meio aos enormes pianos de cauda, lembra a fotografia do próprio John Cage sentado num banquinho, tocando um instrumento infantil na peça Suite for Toy Piano (1948). Conforme descreve a pesquisadora e professora da UFMG Maria Angélica Melendi ${ }^{17}$, "as grandes mãos do homem brincam no pequeno teclado, as costas se curvam à altura do teclado, os joelhos alcançam os cotovelos". Ao se curvarem, Márcia X e John Cage involuem criadoramente, ganham uma estatura pequena, estão em um limiar com a infância onde podem jogar perigosamente com seus brinquedos: um velocípede e um piano infantil.

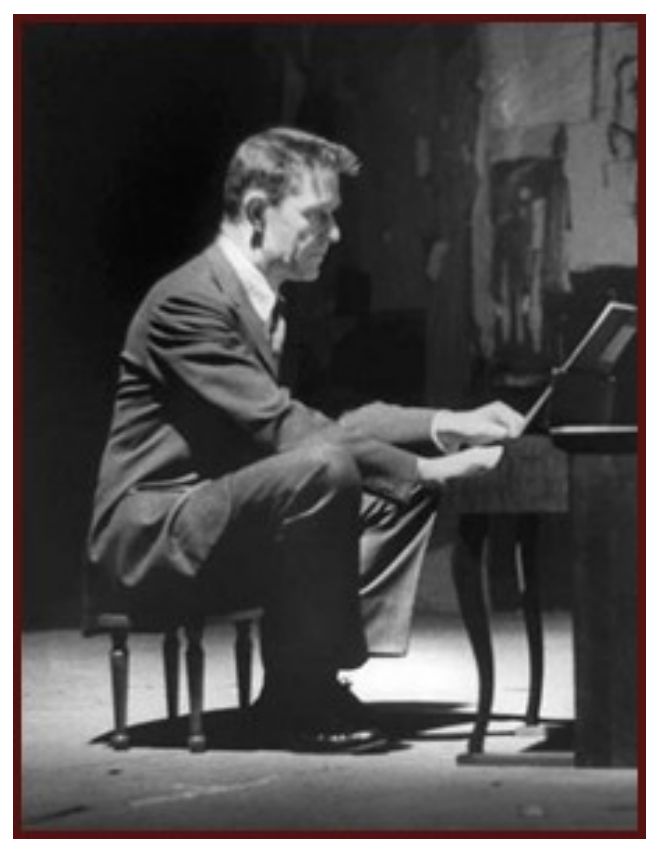

Figura 14: John Cage, Suite for Toy Piano, 1948

Guardadas as diferenças óbvias, essa dimensão de perigo, própria dos jogos da infância, é o que o leva Marcel Duchamp a colocar em uma caixa reproduções em miniatura de seus trabalhos. Construída durante a segunda grande guerra, a caixa de Duchamp, espécie de "pequeno museu portátil", abriga réplicas em ponto pequeno de suas obras, como $\mathrm{O}$ grande vidro [La mariée mise à nu par ses célibataires, même ou Le Grand Verre] e reproduções tridimensionais de ready-mades. Feita de madeira e de uma valise de couro com alça, a primeira Caixa-valise [Boîte-em-valise] só ficou pronta em janeiro de 1941, quando as tropas alemãs já tinham invadido Paris e a vida ali tornava-se incerta. Lembrando retábulos medievais, como observam alguns comentaristas ${ }^{18}$, a Caixa-valise contém 69 miniaturas de obras de Duchamp ou de Rrose Sélavy (do lado de fora da caixa lê-se escrito à mão "de ou par Marcel Duchamp ou Rrose Sélavy") dispostas em divisórias e aberturas deslizantes e desdobráveis. A miniaturização como procedimento, ou seja, a redução da obra de Duchamp a um tamanho apropriado à mala, independentemente de sua escala original, serviu ao artista como garantia de sobrevivência durante os anos da guerra e também como estratégia para ocultar seus trabalhos futuros, já que algumas caixas foram enviadas para Nova York como "utensílios 
domésticos". ${ }^{19}$ A portabilidade da miniatura, como afirma Susan Sontag ${ }^{20}$, é a forma ideal de possuir as coisas para um nômade, ou um refugiado, como Benjamin e Duchamp.

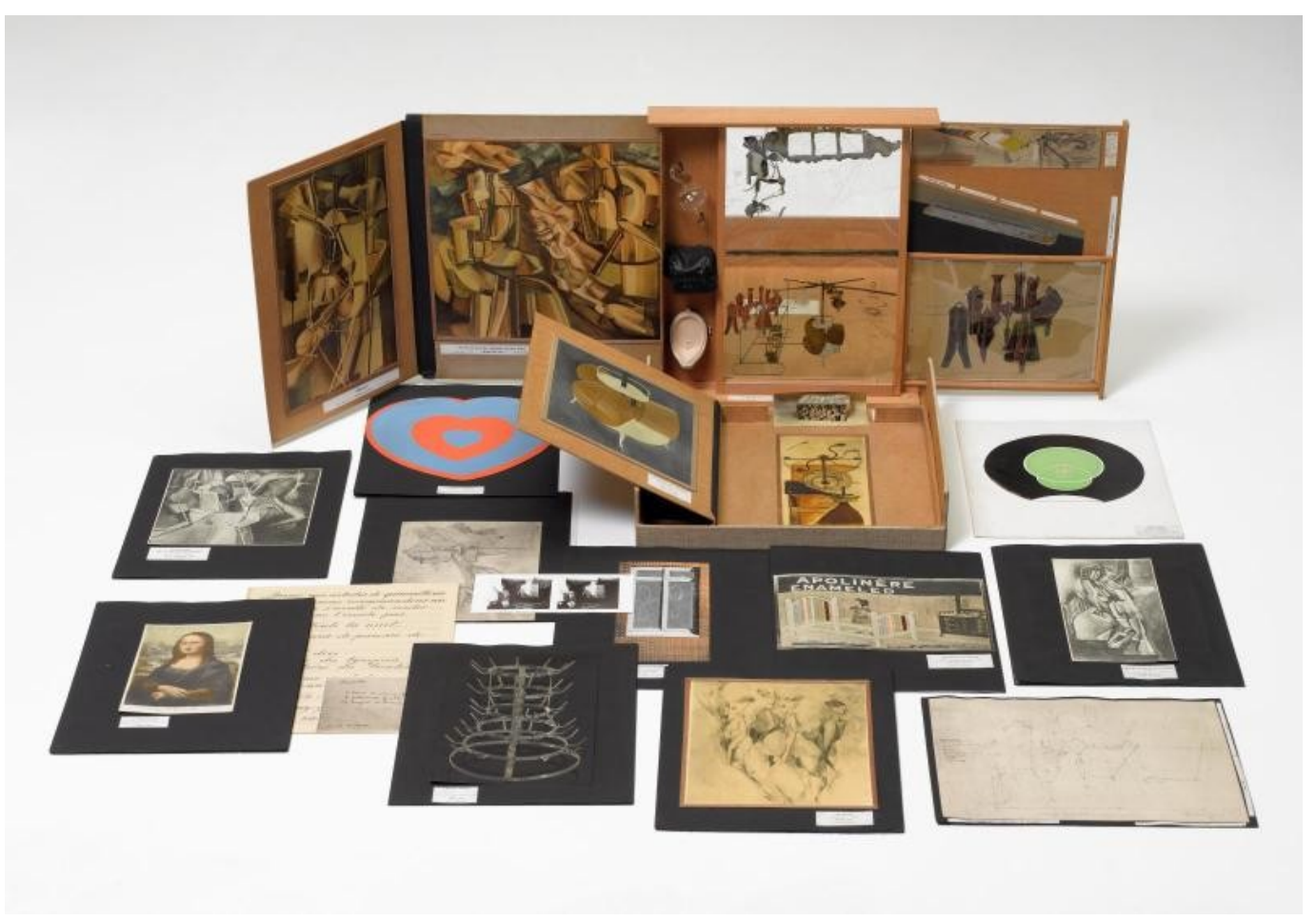

Figura 15: Boîte-en-valise, Duchamp, 1941

A produção plástica do autodidata Arthur Bispo do Rosário possui semelhanças com as de Duchamp, como alguns especialistas vêm apontando, a exemplo de Paulo Herkenhoff e Marta Dias. ${ }^{21}$ Ao contrário das sofisticadas caixas de Duchamp (a Caixa-valise, a Caixa verde [La boîte verte] e a Caixa branca [La boîte blanche]) - a Caixa dos escolhidos de Bispo do Rosário é um objeto rudimentar, feito de madeira, onde ele, o enviado, arquivava nomes de pessoas que deveriam ser conduzidas ao céu. 


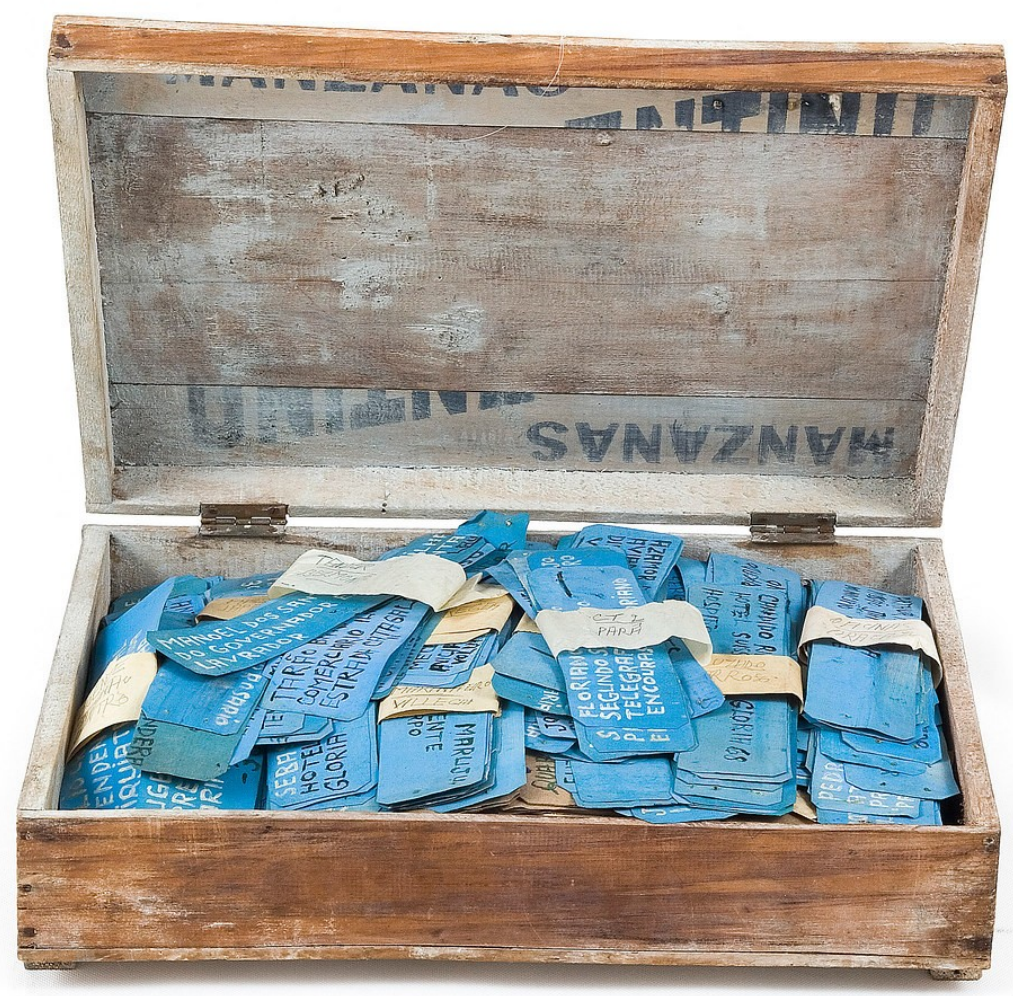

Figura 16: Caixa dos escolhidos, Bispo do Rosário, s/d

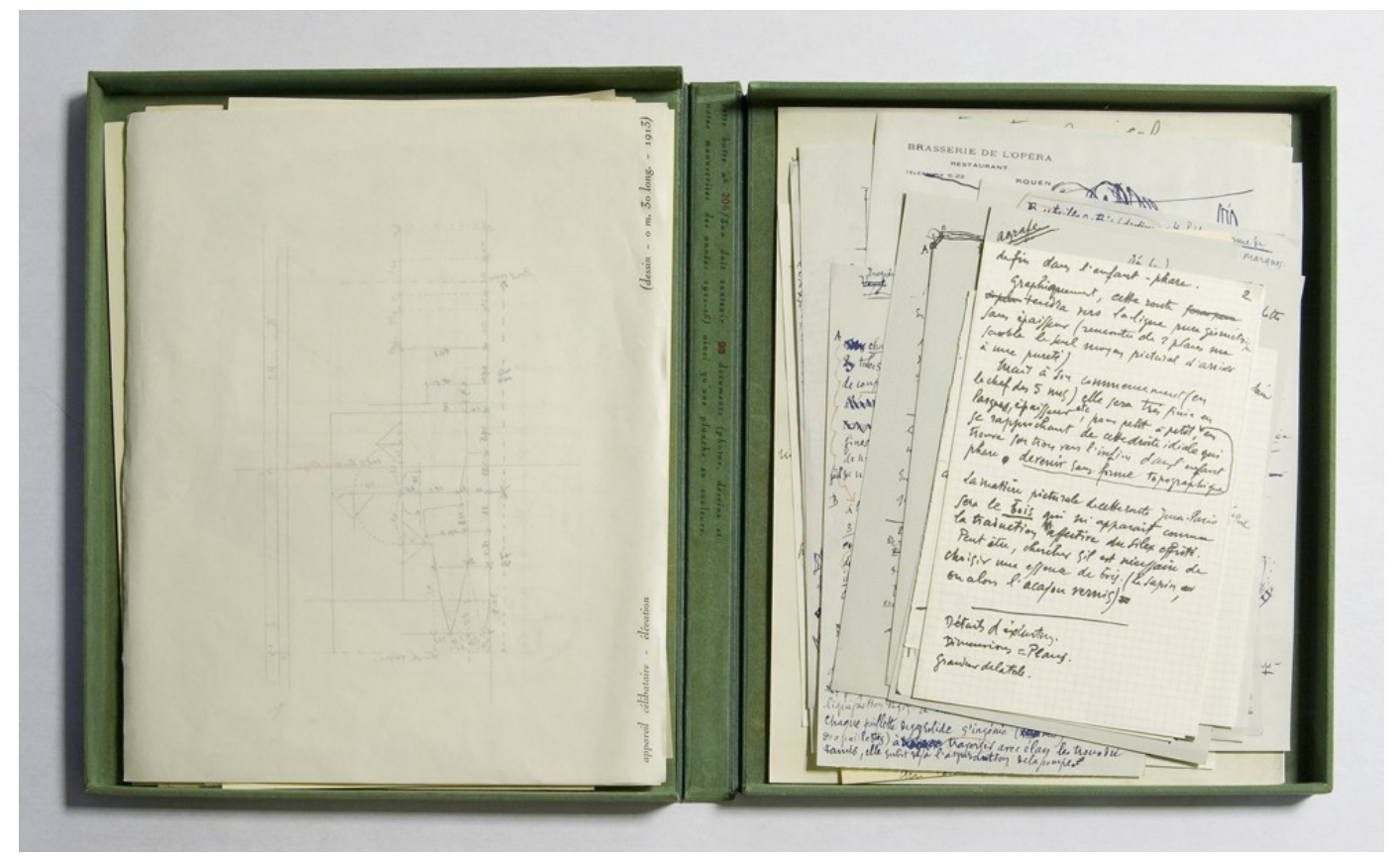

Figura 17: La boîte verte, Duchamp, 1914 


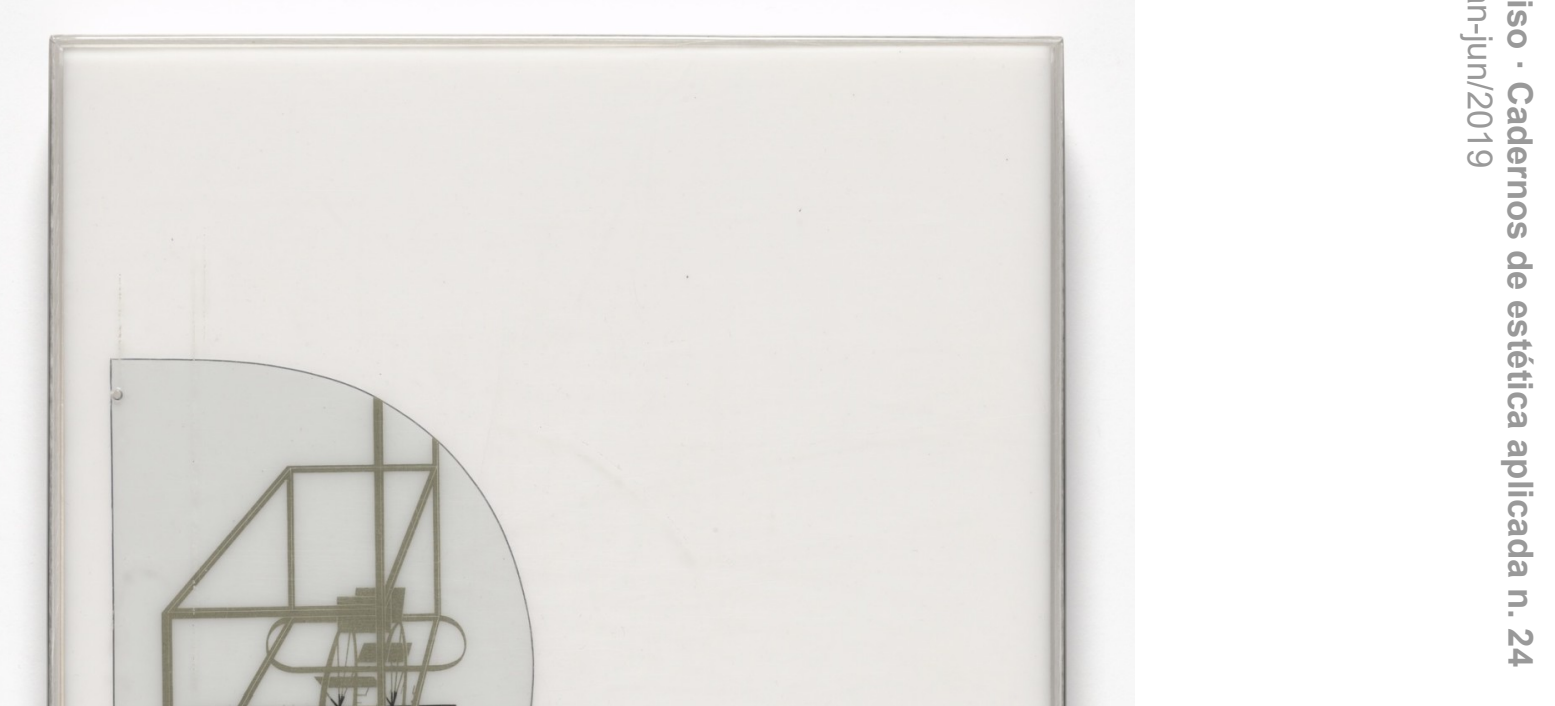

Figura 18: À l'infinitif (La boîte blanche), Duchamp, 1912-20

Na mesma época em que Duchamp começou a apropriar-se de objetos industriais no âmbito da arte e a construir sua Caixa-valise, Bispo do Rosário passou a recolher artefatos que registrassem sua passagem pela Terra, os quais seriam apresentados à divindade no dia do Juízo Final. A partir de então, o antigo marinheiro empenhou-se com afinco e obstinação na missão para a qual fora assinalado: construiu uma coleção de objetos manufaturados feitos de materiais diversos (metal, vidro, madeira, lata, papelão, tecido etc.), anotou em pedaços de papel o nome dos escolhidos e bordou fardões e majestosos mantos, que cobriam sua cama-nave. Recolhido à cela da instituição psiquiátrica onde passou cerca de 50 anos, dedicou-se também ao dispendioso exercício de encobrir alguns objetos até esconder o material de que eram feitos. Com linhas azuis desfiadas do seu uniforme manicomial ou de seus companheiros, enrolava brinquedos, embarcações, utensílios domésticos, materiais hospitalares, alguns em tamanho real, outros miniaturizados, como um patinete, um tamborim e bandeiras de navio. ${ }^{22}$ 

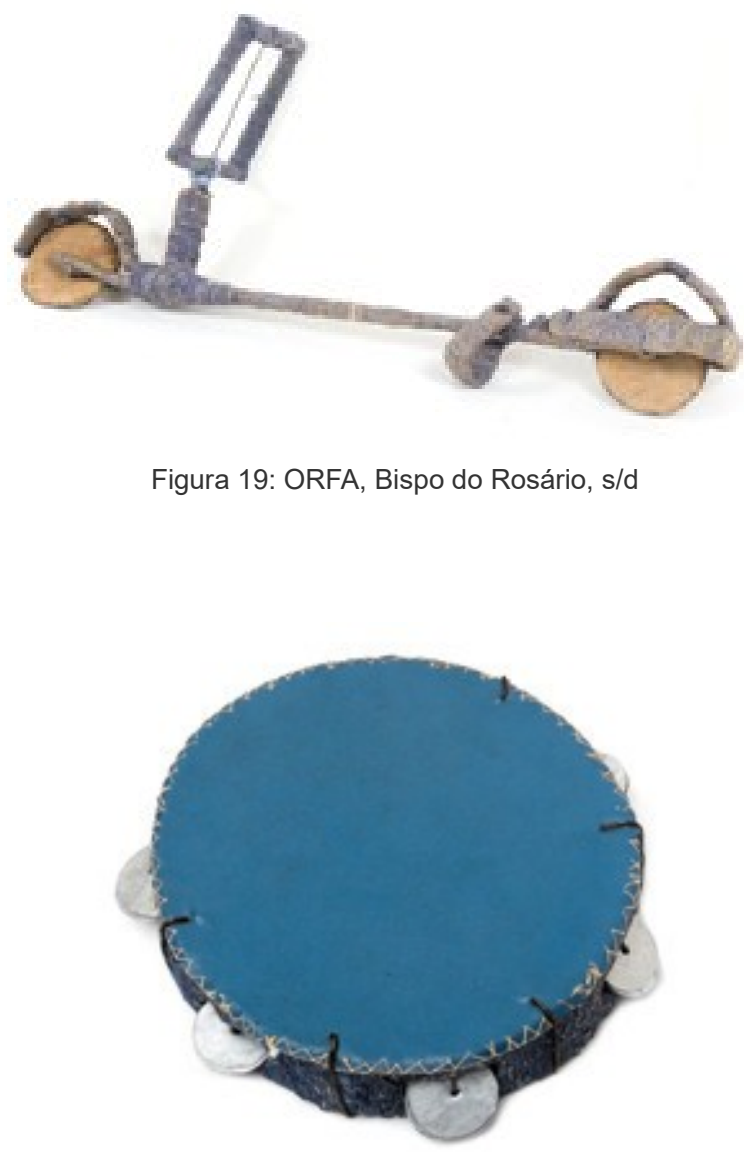

Figura 20: ORFA, Bispo do Rosário, s/d

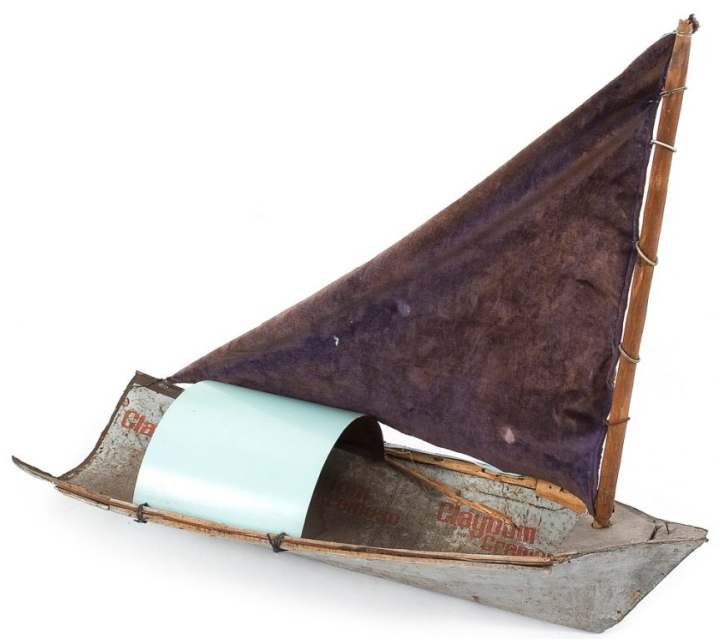

Figura 21: ORFA, Bispo do Rosário, s/d 
Os Objetos Recobertos de Fio Azul (ORFAs) ${ }^{23}$, miniaturizados ou não, perdem sua função utilitária ao serem encapsulados fio a fio pelo artista colecionador, ganhando, por conseguinte, uma dimensão mística e mágica na medida em que representam o que deve ser preservado no mundo pós-apocalíptico para o qual Bispo do Rosário estava se preparando. Assim como as crianças no "Canteiro de obra" benjaminiano, que constroem um "pequeno mundo dentro do grande" com aquilo que resta do trabalho da construção, da costura ou da marcenaria, o habilidoso artesão Bispo do Rosário mumifica e/ou miniaturiza coisas precárias com extremo requinte e precisão manual, para apresentá-las à divindade.

A harmonia secreta da desarmonia: quero não o que está feito mas o que tortuosamente ainda se faz. Minhas desequilibradas palavras são o luxo de meu silêncio. Escrevo por acrobáticas e aéreas piruetas - escrevo por profundamente querer falar. Embora escrever só esteja me dando a grande medida do silêncio. ${ }^{24}$

Já Clarice Lispector, a seu modo, também uma colecionadora de "existências mínimas"25, construiu, em um dos seus contos, uma figura minúscula, enigmática e sedutora: "A menor mulher do mundo". Na África Equatorial, um etnógrafo francês descobre uma tribo de uma pequenez surpreendente; mais surpreso ele fica quando é informado de que, no fundo das florestas africanas, existe um povo ainda menor, cuja linguagem é breve e simples. É no topo de uma árvore que o pesquisador Marcel Pretre encontra uma pigmeia de $45 \mathrm{~cm}$, uma "coisa rara" a quem nomeia de Pequena Flor. O encontro com a "coisa humana menor que existe", ali "toda em pé e a seus pés", causa-lhe vertigem e espanto: Pequena Flor está grávida, traz dentro de si um "filho mínimo", outra "existência mínima".

A fotografia da mulher de quarenta e cinco centímetros, negra e grávida, estampa os jornais de domingo e produz afetos diversos nas famílias de classe média. Em um apartamento, uma família afixa, junto à imagem da menor mulher do mundo, uma fita métrica e dá-se à tarefa de verificar o tamanho daquele pequeno ser. Noutra casa, um menino quer assustar o irmão com a imagem da minúscula mulher. A brincadeira da criança faz a mãe lembrar-se de uma história que a cozinheira lhe contara do tempo do orfanato e que diz do caráter violento e muitas vezes erótico das brincadeiras infantis:

Não tendo boneca com que brincar [...] as meninas sabidas haviam escondido da freira a morte de uma das garotas. Guardaram o cadáver num armário até a freira sair, e brincaram com a menina morta, deram-Ihe banhos e comidinhas, puseram-na de castigo somente para depois poder beijá-la, consolando-a. ${ }^{26}$

Também este conto de Clarice é um pequeno brinquedo, uma boneca russa, de onde surgem, parágrafo a parágrafo, imagens de estranhamento, repugnância, crueldade, carinho e erotismo. Escrito como se fosse "uma caixa dentro de uma caixa, dentro de uma caixa"27, o conto toca o menos, o pouco, o nada, uma "existência mínima". Tão pequenina e, por isso mesmo, completa e irredutível. Concentrado naquela pequenez, o 
riso bestial, delicado e inclassificável de Pequena Flor perturba etnógrafo e leitor "como só home[ns] de tamanho grande se perturba[m]"; perturba porque é riso de amor: "e amor é não ser comido". ${ }^{28}$

A menor mulher do mundo de Clarice, as caixas de Duchamp e de Bispo do Rosário, os brinquedos eróticos de Márcia $X$, os mundos liliputianos esculpidos em agulhas e alfinetes por Willard Wigan, o pensador alemão de letra minúscula e colecionador de brinquedos são uma pequena amostra da coleção de imagens recolhidas por um pesquisador - ao modo do "Corcundinha" -, que aposta nas ações de colecionar e miniaturizar e no cruzamento de escritores e artistas com o universo da infância.

\section{bibliografia complementar}

BENJAMIN, W. Imagens de pensamento / Sobre o haxixe e outras drogas. Tradução de João Barrento. Belo Horizonte: Autêntica, 2013, pp. 97-99.

"A doutrina das semelhanças". In: Magia e técnica, arte e política: ensaios sobre literatura e história da cultura. Obras escolhidas I. Tradução de Sérgio Paulo Rouanet. São Paulo: Brasilense, 2012

GAGNEBIN, J.- M. "A criança no limiar do labirinto". In: História e memória em Walter Benjamin. São Paulo: Perspectiva, 2013, pp. 73-92.

MARX, U. et al. Walter Benjamin's Archive: Images, Texts, Signs. Londres: Verso, 2007.

\section{* Francisco Camêlo é doutorando em filosofia pela PUC-RIO.}

* Agradeço às professoras Rosana Kohl Bines e Marília Rothier Cardoso, ambas da PUC-Rio, pela leitura interessada e pelos comentários à versão inicial do texto.

${ }^{1}$ Tradução de Jeanne Marie Gagnebin (2013).

${ }^{2}$ Utilizo a feliz expressão de Gerhard Richter em seu livro recentemente traduzido no Brasil e referido ao final do trabalho.

${ }^{3}$ Leitor dos românticos alemães e de Friedrich Nietzsche, Walter Benjamin não se refere à forma de escrita da Infância como "fragmento" ou "aforisma". Ele utiliza a palavra "Stück", que pode ser traduzida tanto por "peça" (de jogo, de teatro) como "pedaço" (de bolo). Agradeço à pesquisadora Juliana Lugão (UFF) pela referência ao uso deste termo por Benjamin, que o utiliza muito na correspondência com Gershom Scholem.

${ }^{4}$ ADORNO, T. "Caracterização de Walter Benjamin". In: Prismas: crítica cultural e sociedade. Tradução de Augustin Wernet e Jorge Mattos Brito de Almeida. São Paulo: Ática, 2001, pp. 223237, aqui pp. 224-225.

${ }^{5}$ BENJAMIN, W. Rua de mão única: Infância berlinense: 1900. Tradução de João Barrento. Belo Horizonte: Autêntica, 2013, p. 126.

${ }^{6}$ Idem. Passagens. Organização de Willi Bolle e Olgário Chain Féres Matos. Tradução de Irene Aron e Cleonice Paes Barreto Mourão. Belo Horizonte: Editora UFMG; São Paulo: Imprensa Oficial do Estado de São Paulo, 2009.

7 MOLDER, M. F. "A paixão de colecionar em Walter Benjamin". In: Semear na neve. Lisboa: Relógio D’Água Editores, 1999. pp. 40-54. 
${ }^{8}$ ARENDT, H. "Walter Benjamin (1892-1940)". In: Homens em tempos sombrios. Tradução de Denise Bottmann. São Paulo: Companhia das Letras, 2008, pp. 165-222.

9 SONTAG, S. "Sob o signo de saturno". In: Sob o signo de Saturno. Tradução de Ana Maria Capovilla e Albino Poli Jr. Porto Alegre: L\&PM, 1986, pp. 85-103.

${ }^{10}$ RICHTER, G. Imagens de pensamento: reflexões dos escritores da Escola de Frankfurt a partir da vida danificada. Tradução de Fabio Akcelrud Durão. São Paulo: Nankin, 2017.

${ }^{11}$ SONTAG, S. Op. cit.

12 Cf. <https://www.ted.com/talks/willard_wigan_hold_your_breath_for_micro_sculpture>. Acesso em: 23.04. 2018.

${ }^{13}$ ANTELO, R. Maria com Marcel: Duchamp nos trópicos. Belo Horizonte: Editora UFMG, 2010.

${ }^{14}$ Cf. <http://marciax.art.br/mxTexts.asp?sMenu=3\&sTipo=4>. Acesso em: 24.04.2018.

${ }^{15}$ BENJAMIN, W. Rua de mão única. Op. cit., p. 150.

${ }^{16}$ Cf. <https://performatus.net/entrevistas/alex-hamburger/>. Acesso em: 24.04.2018.

${ }^{17}$ MELENDI, M. A. "Mãos pequenas: a infância como sonho e como fantasmagoria". In: Estratégias da arte em uma era de catástrofes. Rio de Janeiro: Cobogó, 2017, pp. 211-232, aqui p. 230.

${ }^{18}$ Cf. MACK, J. The Art of Small Things. Londres: The British Museum Press, 2007., p. 83.

19 TOMKINS, C. Duchamp: uma biografia. Tradução de Maria Thereza de Rezende Costa. São Paulo: Cosac Naify, 2013.

${ }^{20}$ SONTAG, S. Op. cit.

${ }^{21}$ Ver a propósito o ensaio "A vontade de arte e o material existente na Terra dos homens", de Paulo Herkenhoff e o livro Arthur Bispo do Rosário: a poética do delírio, de Marta Dantas.

${ }^{22}$ Agradeço ao pesquisador João Henrique Queiroz (UERJ) a gentileza de disponibilizar as ORFAs reproduzidas neste trabalho.

${ }^{23}$ Termo cunhado por Frederico Moraes.

${ }^{24}$ LISPECTOR, C. Água viva. Rio de Janeiro: Rocco, 1998, pp. 12-13.

${ }^{25}$ Quero com isto, em um trabalho futuro, ler o conto de Clarice a partir das considerações de David Lapoujade sobre Étiènne Souriau, em As existências mínimas.

${ }^{26}$ LISPECTOR, Clarice. A menor mulher do mundo. In: Laços de família. Rio de Janeiro: Rocco, 2009 , p. 68-75, aqui p. 71.

${ }^{27}$ Ibidem, p. 68.

${ }^{28}$ Ibidem, p. 75. 